\title{
Sera from children with active Henoch-Schönlein purpura can enhance the production of interleukin 8 by human umbilical venous endothelial cells
}

\author{
Y H Yang, H J Lai, C M Huang, L C Wang, Y T Lin, B L Chiang
}

Ann Rheum Dis 2004;63:1511-1513. doi: 10.1136/ard.2003.016196

\begin{abstract}
Objective: To investigate the ability of sera from children with active Henoch-Schönlein purpura (HSP) to enhance endothelial interleukin (IL) 8 production and intercellular adhesion molecule (ICAM)-1 expression.

Methods: Nine children with active HSP and nine normal healthy children were enrolled. IL8 serum levels of patients and controls at different stages were analysed. Production of IL8 and expression of ICAM-1 by human umbilical venous endothelial cells were detected (ELISA for IL8, flow cytometry for ICAM-1) and compared under various stimuli, including sera of patients at different stages, sera of controls, and medium alone.

Results: Serum levels of IL8 were increased at the acute stage. Levels of IL8 in supernatants from human umbilical venous endothelial cells (HUVEC) co-cultured with sera from children with active HSP were significantly higher than those from HUVEC without any treatment $(p=0.001)$, HUVEC treated with inactive sera $(p=0.004)$, and HUVEC treated with sera from healthy controls $(p=0.004)$. Sera from patients and from controls did not enhance the expression of ICAM- 1 on HUVEC.

Conclusions: Some factors may be present in sera from children with active HSP that could activate endothelial cells to produce IL8. This process may account, in part, for the mechanisms of perivascular neutrophil infiltration and leucocytosis in HSP.
\end{abstract}

$\mathrm{H}$ enoch-Schönlein purpura (HSP) is one of the most common small vessel forms of vasculitis in children. At the acute stage, it is characterised by peripheral leucocytosis and perivascular infiltration with polymorphonuclear neutrophils (PMNs). ${ }^{1}$

Interleukin (IL) 8 belongs to the $\mathrm{C}$-X-C chemokine subfamily. A variety of different cells, including monocytes, epithelial cells, and endothelial cells, can produce IL8 under certain stimuli. ${ }^{2}$ The ability of IL8 to liberate neutrophils from the bone marrow reservoir and to stimulate movement of neutrophils across endothelial monolayers suggests that this molecule may participate in the pathogenesis of many inflammatory diseases. ${ }^{34}$ The activation of intercellular adhesion molecule (ICAM)- 1 is another important factor in the migration of PMNs from blood vessels. ${ }^{5}$ The interaction between endothelial ICAM-1 and lymphocyte function associated antigen-1/macrophage-1 on PMNs induces leucocytes to bind tightly to endothelium and allows these PMNs to squeeze between the endothelial cells.

To investigate the roles of IL8, ICAM-1, and endothelial cells in the pathogenesis of HSP we analysed the serum levels of IL8 in children with HSP at different stages and those in healthy children, and designed experiments to clarify the relationship among HSP, IL8, ICAM-1, and endothelial cells.

\section{PATIENTS AND METHODS}

\section{Patients and IL8 detection}

Nine children ( six male, three female) diagnosed with active HSP according to American College of Rheumatology 1990 criteria at National Taiwan University Hospital and another nine normal healthy children matched for age and sex were enrolled in the study. Informed consent and institutional approval were obtained from their parents. Whole blood $(10 \mathrm{ml})$ from patients in the acute stage and before antiinflammatory treatment, patients at the convalescent stage (2-3 months after the current episode, without any signs and symptoms of HSP), and healthy controls was sampled. The serum levels of IL8 were analysed by commercial enzyme linked immunosorbent assay (ELISA) kits (Bender MedSystems, Austria) according to the protocols of the manufacturers.

\section{Culture of human umbilical venous epithelial cells (HUVEC)}

Endothelial cells were obtained from human umbilical vein by collagenase (Gibco BRL, Life Technologies) digestion. The separated cells were seeded in $75 \mathrm{ml}$ flasks precoated with $1 \%$ gelatin solution and grown in medium 199 (Gibco BRL, Life Technologies) supplemented with $15 \%$ heat inactivated fetal calf serum, heparin sulphate, L-glutamine, endothelial cell growth factor (BM) (final concentration, $20 \mu \mathrm{g} / \mathrm{ml}$ ), and $100 \mu \mathrm{g} / \mathrm{ml}$ penicillin/streptomycin. All cultures were incubated at $37^{\circ} \mathrm{C}$ in $5 \% \mathrm{CO}_{2}$, and the cells were used between the 2nd and the 6th passage.

\section{IL8 release under various stimuli}

HUVEC were seeded on gelatin coated, 96 well microtitre plates (Nunc, Demark) at a concentration of $1 \times 10^{4}$ cells/well. When the cellular growth became confluent 3-4 days later, each well was washed twice with phosphate buffered saline, and $150 \mu \mathrm{l}$ serum-free medium (medium 199) was added. Sera $(50 \mu \mathrm{l})$ from patients at different stages and controls were co-cultured with the cells for 2 hours at $37^{\circ} \mathrm{C}$ in $5 \% \mathrm{CO}_{2}$. The medium and serum were discarded. After washing, the cells were incubated with medium 199 at $37^{\circ} \mathrm{C}$ in $5 \% \mathrm{CO}_{2}$ for a further 24 hours, and the supernatants were then collected. Finally, the concentrations of IL8 of all supernatants were determined by commercial ELISA kits.

Abbreviations: ELISA, enzyme linked immunosorbent assay; HSP, Henoch-Schönlein purpura; HUVEC, human umbilical venous epithelial cells; ICAM, intercellular adhesion molecule; IL, interleukin; PMNs, polymorphonuclear neutrophils; TNF $\alpha$, tumour necrosis factor $\alpha$ 


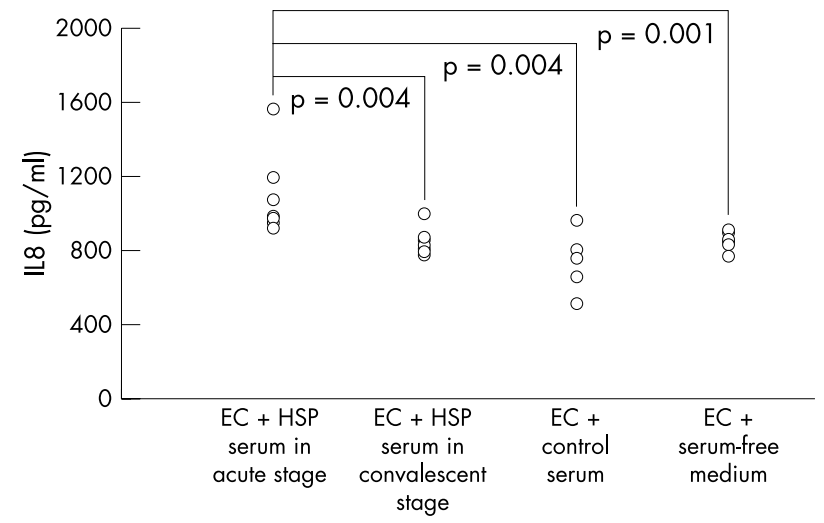

Figure 1 The supernatant IL8 levels of HUVEC incubated with serumfree medium (medium 199)+sera from children with active HSP, HUVEC incubated with medium 199+sera from patients during the convalescent stage, HUVEC incubated with medium 199+sera from normal healthy controls, and HUVEC cultured in medium 199 alone.

Flow cytometry for ICAM- 1 expression

HUVEC at a density of $1 \times 10^{5}$ cells/well were seeded in $1 \%$ gelatin coated, 12 well plates with complete medium and incubated at $37^{\circ} \mathrm{C}$ in $5 \% \mathrm{CO}_{2}$ for 3 days. The medium was removed and $800 \mu \mathrm{l}$ medium 199 was added to each well. Sera from patients with active HSP $(200 \mu \mathrm{l})$, sera from healthy controls $(200 \mu \mathrm{l})$, and tumour necrosis factor $\alpha$ $(\mathrm{TNF} \alpha)(10 \mathrm{ng} / \mathrm{ml})$ were co-incubated for 24 hours. The time chosen has been reported to be optimal for the study of ICAM-1 expression on endothelial cells with other stimuli. ${ }^{6}$ After incubation, the cells were detached from the plates and washed. The cell suspension was centrifuged, the supernatant was discarded, and the pellet was resuspended. These cells were then stained by adding phycoerythrin conjugated mouse antihuman ICAM-1 (CD54) monoclonal antibody (Serotec, USA) for 1 hour. Isotype matched control mouse IgG was used to eliminate non-specific bindings. The final results were analysed using FACSort (Becton Dickinson, USA).

\section{Statistical analysis}

The values of IL8, and the mean fluorescence intensity of ICAM-1 expression on HUVEC were expressed as mean (SEM). Each two-group comparison was conducted using the Mann-Whitney $U$ test. A two tailed $p$ value $<0.05$ was considered significant.

\section{RESULTS}

\section{Patients' characteristics and serum levels of IL8}

All patients had typical skin purpura, seven of nine patients had abdominal angina and arthritis, and only one patient had glomerulonephritis. The serum levels of IL8 in patients with active HSP were significantly higher than those in normal healthy controls (24l.5 (83.3) pg/ml $v 5.8$ (4) pg/ml, respectively, $\mathrm{p}=0.02$ ). During the convalescent stage, the IL8 serum levels of all patients were undetectable.

\section{Patients' sera induced IL8 release}

HUVEC are primary human endothelial cells, which, in vitro, without any stimulation, would spontaneously release IL8 when cultured in serum-free medium (fig 1). The IL8 levels in supernatants of HUVEC incubated with serum-free medium plus sera from children with active HSP were significantly higher than the levels in supernatants of HUVEC in serum-free medium alone $(1060.5$ (69.3) $\mathrm{pg} / \mathrm{ml} v 854.7$ (18.1) $\mathrm{pg} / \mathrm{ml}, \mathrm{p}=0.001$ ), higher than HUVEC incubated with serum-free medium plus sera from patients at the
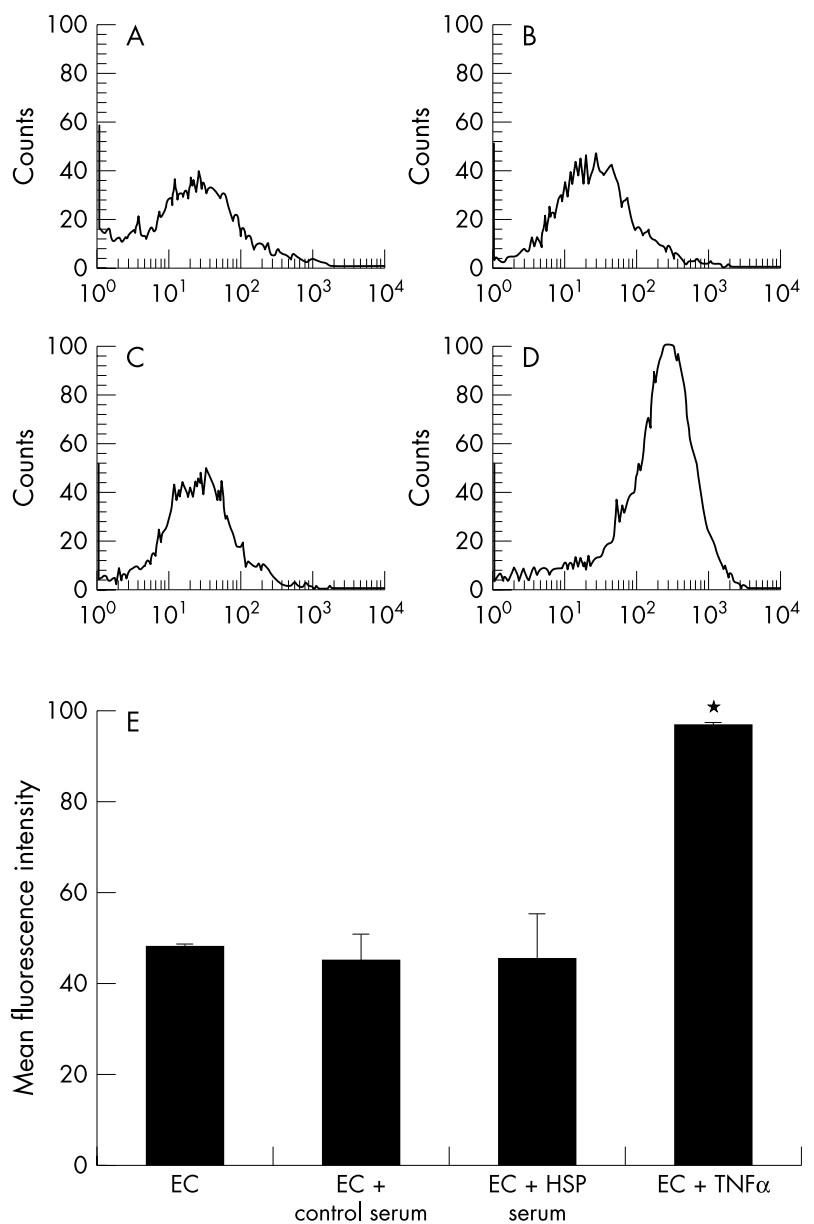

Figure 2 ICAM- 1 expression on HUVEC incubated with $(A)$ serum-free medium alone; (B) sera from children with active HSP; (C) sera from healthy controls; and (D) TNF $\alpha$ (10 ng/ml) for 24 hours. (E) The mean fluorescence intensity of ICAM-1 expression on HUVEC under different stimuli (arbitrary units $0-100$ ). ${ }^{*} \mathrm{p}<0.001$.

convalescent stage (1060.5 (69.3) pg/ml $v 851.6$ (21.3) pg/ml, $\mathrm{p}=0.004)$, and higher than HUVEC incubated with serumfree medium and sera from normal healthy controls (1060.5 (69.3) $\mathrm{pg} / \mathrm{ml} v 735.2$ (52.4) $\mathrm{pg} / \mathrm{ml}, \mathrm{p}=0.004$ ) (fig $\mathrm{l}$ ).

\section{ICAM- 1 expression}

The mean fluorescence intensity of ICAM-1 expression on HUVEC without any stimuli was around 50 (arbitrary units, with a range $0-100$ ) (figs $2 \mathrm{~A}$ and $\mathrm{E}$ ). TNF $\alpha$ at a concentration of $10 \mathrm{ng} / \mathrm{ml}$ that highly activates the HUVEC to express ICAM-1 (97.3 (0.1) v $48(0.8), \mathrm{p}<0.001)$ was a positive control (figs 2D and E). Incubation of HUVEC with either sera from patients with active HSP or those from normal healthy controls had negligible effect on the expression of ICAM- 1 at 4 hours (data not shown), and 24 hours (figs $2 \mathrm{~B}$, C, and E).

\section{DISCUSSION}

In this study we showed that children with HSP had raised serum levels of IL8 during the acute stage, and the active sera enhanced the endothelial IL8 production. IL8 is a powerful chemoattractant, and has been found to play a part within many clinicopathological conditions, including immune mediated vasculitis. ${ }^{34} 7$

In addition to vascular deposition of immune complexes containing $\operatorname{IgA}$, perivascular accumulation of PMNs is another histopathological feature of HSP. ${ }^{1}$ These PMNs are 
thought to be effector cells, leading to vascular damage. Many investigators have shown that activated neutrophils injure endothelial cells through the generation of reactive oxygen metabolites and the release of granule protease. ${ }^{8-10}$ We suggested in this study that certain factors in sera of children with active HSP might interact with endothelial cells, and the activated endothelial cells could then produce some potent chemoattractants, such as IL8, and enhance the expression of adhesion molecules. Our results showed that sera from children with active HSP did enhance the production of IL8 by HUVEC compared with sera from children with inactive HSP, and sera from healthy children. When the disease subsided, these stimulatory factors seemed to decline gradually. IL8 is essential for the growth and proliferation of endothelial cells, ${ }^{11}$ and this may be the reason why endothelial cells secrete IL8 persistently, even when cultured in serum-free medium. As the level of IL8 increases, the effects of attraction and activation of PMNs develop. ${ }^{12}$

The process of recruitment of PMNs to inflammation sites comprises not only chemotactic factor IL8 but also adhesion molecules expressed on PMNs and endothelial cells. E-selectin and ICAM-1, two most important adhesion molecules on endothelial cells, are responsible for the rolling adhesion and the tight binding, respectively. E-selectin appears within a few hours after exposure to stimuli, and this is followed by the massive expression of ICAM-1 24 hours later. ${ }^{5}$ In some recent studies, circulating soluble ICAM-1 and E-selectin concentrations did not differ significantly between patients with active HSP and healthy controls. ${ }^{13}{ }^{14}$ In this study we focused on the expression of ICAM-1 on HUVEC by flow cytometry analysis. Although TNF $\alpha$ highly induced the expression of endothelial ICAM-1 in vitro, sera from children with active HSP could not enhance the ICAM-1 expression at different times: 4 hours and 24 hours. Our results seem to be in agreement with those of Gattorno et al, who concluded in their study that TNF $\alpha$ induced adhesion molecules appeared to have a minor role in the pathogenesis of HSP. ${ }^{15}$

In conclusion, sera from children with active HSP did not enhance the expression of endothelial ICAM-1, but might contain factors that could activate endothelial cells to release large amount of IL8. The increased IL8 may contribute, in part, to the perivascular accumulation of PMNs and leucocytosis in HSP. To identify the real activating factors in HSP, more studies are needed.

\section{ACKNOWLEDGEMENTS}

This study was supported by a grant from the National Science Council, Republic of China (NSC-92-2314-B-002-223).

\section{Authors' affiliations}

Y H Yang, H J Lai, C M Huang, L C Wang, Y T Lin, B L Chiang,

Department of Paediatrics, National Taiwan University Hospital, College of Medicine, National Taiwan University, Taipei, Taiwan

Correspondence to: $\operatorname{Dr}$ B L Chiang, Department of Paediatrics, National Taiwan University Hospital, 7 Chung-Shan South Road, Taipei, Taiwan; gicmbor@ha.mc.ntu.edu.tw

Accepted 27 January 2004

\section{REFERENCES}

1 Ballinger S. Henoch-Schönlein purpura. Curr Opin Rheumatol 2003; 15:591-4.

2 Baggiolini M, Walz A, Kunkel SL. Neutrophil activating peptide-1/interleukin 8, a novel cytokine that activates neutrophils. J Clin Invest 1989;84:1045-9.

3 Bosch I, Xhaja K, Estevez L, Raines G, Melichar H, Warke RV, et al. Increased production of interleukin-8 in primary human monocytes and in human epithelial and endothelial cell lines after dengue virus challenge. J Virol 2002;76:5588-97.

4 Hirani N, Antonicelli F, Strieter RM, Wiesener MS, Ratcliffe PJ, Haslett C, et al. The regulation of interleukin- 8 by hypoxia in human macrophages $-a$ potential role in the pathogenesis of the acute respiratory distress syndrome (ARDS). Mol Med 2001;7:685-97.

5 Janeway CA, Travers $P$, Walport M, Shlomchik MJ. Immunobiology, 5th ed. USA: Garland Churchill Livingstone NY, 2001:74-7.

6 Yazici ZA, Raschi E, Patel A, Testoni C, Borghi MO, Graham AM, et al. Human monoclonal anti-endothelial cell IgG-derived from a systemic lupus erythematosus patient binds and activates human endothelium in vitro. Int Immunol 2001;13:349-57.

7 Cheon H, Yu SJ, Yoo DH, Chae IJ, Song GG, Sohn J. Increased expression of pro-inflammatory cytokines and metalloproteinase-1 by TGF-betal in synovial fibroblasts from rheumatoid arthritis and normal individuals. Clin Exp Immunol 2002; 127:547-52.

8 Weiss SJ, Curnutte JT, Regiani S. Neutrophil-mediated solubilization of the subendothelial matrix: oxidative and nonoxidative mechanisms of proteolysis used by normal and chronic granulomatous disease phagocytes. J Immunol 1986;136:636-41.

9 Soylemezoglu O, Ozkaya O, Erbas D, Akkok N, Buyan N, Hasanoglu E. Nitric oxide in Henoch-Schonlein purpura. Scand J Rheumatol 2002;31:271-4.

10 Erdogan O, Oner A, Aydin A, Isimer A, Demircin G, Bulbul M. Effect of vitamin $E$ treatment on the oxidative damage occurring in Henoch-Schonlein purpura. Acta Paediatr 2003;92:546-50.

11 Li A, Dubey S, Varney ML, Dave BJ, Singh RK. IL-8 directly enhanced endothelial cell survival, proliferation, and matrix metalloproteinases production and regulated angiogenesis. J Immunol 2003;170:3369-76.

12 Takahashi M, Ikeda U, Kasahara T, Kitagawa S, Takahashi Y, Shimada K, et al. Activation of human monocytes for enhanced production of interleukin 8 during transendothelial migration in vitro. J Clin Immunol 1997; 17:53-62.

13 Furukawa S, Imai K, Matsubara T, Yone K, Yachi A, Okumura K, et al. Increased levels of circulating intercellular adhesion molecule 1 in Kawasaki disease. Arthritis Rheum 1992;35:672-7.

14 Soylemezoglu O, Sultan N, Gursel T, Buyan N, Hasanoglu E. Circulating adhesion molecules ICAM-1, E-selectin, and von Willebrand factor in Henoch Schonlein purpura. Arch Dis Child 1996:75:507-11.

15 Gattorno M, Vignola S, Barbano G, Sormani MP, Sabatini F, Buoncompagni $A$, et al. Tumor necrosis factor induced adhesion molecule serum concentrations in Henoch-Schonlein purpura and pediatric systemic lupus erythematosus. J Rheumatol 2000;27:2251-5. 